\title{
Planning Customer Relationship Management (CRM) Strategies in the Mining and Industry Bank
}

\author{
Dr Saeed Abesy \\ Assistant Professor, Department of Management \& Economy, Payame Noor University, Tehran, Iran
}

Vahideh Torkan

Department of Management \& Economy, Payame Noor University, Tehran, Iran

Doi:10.5901/mjss.2016.v7n3s3p298

\begin{abstract}
Today, technology has led the organizations to offer their products and services with higher quality and reduced price to their elite customers. For this reason, with the sole use of the advanced technology or cheaper price in comparison to the competitors the competitive advantage cannot be achieved. In this case, a customer is the only reliable competitive advantage for the organizations. The customer relationship management is a business strategy that adopts the absorption, maintenance and the promotions of a customer. With the correct implementation of the customer relationship management (CRM) the organization will be able to conduct the three aforesaid duties with a lower cost and thus preserve its main competitive advantage which is the said customer. In this regard, the planning and compilation of the strategies related to the customer orientation and the implementation and its executions in the organizations that maintain growth, development and a favourable function is the most important principles of success and leads the organizations towards their goals. Accordingly, to achieve the research objectives including identification of the opportunities and threats of the mining and industry bank production in the customer oriented section, the strength and weakness points inside the bank, the determination of the appropriate strategies for the customer oriented bank section, the comprehensive framework of the strategies planning based on the strategic planning of Fred R. David has been used. In the prime stage, the vision and the mission statement of the customer oriented bank (database) has been determined and in the matrix input stage, the external factors evaluation (EFE), and the internal factors evaluation matrix have been prepared. Considering the obtained information in the previous stage, in the comparison and adaptation stage, the SWOT matrix, the internal and external matrix (IE), and the situation assessment matrix and strategic preparation (SPACE) was designed. In the decision making stage, the strategies selection with higher priority was used rather than the quantitative QSPM, the intuitive method - acceptance application, for its feasibility, congruence with goals and utilization of real views of the bank consultants availing more practical and applicable strategies that the most suitable strategy was "conducting effective and efficient advertising in order to increase the public awareness of the bank activities".
\end{abstract}

Keywords: Strategic planning, Customer relationship management, mission, vision, goals, strategy.

\section{Introduction}

The process of strategy planning is a logical, systematic and purposeful process and is founded on the basis of this belief that the organization should constantly review the internal and external events and conduct its related and important environmental changes (Vafaei, Hossein, 2004).

On the other hand, today, the banking manuscript in Iran more than past covers the customer and its importance and thereby how to achieve the satisfaction and loyalty of a customer some researches have been conducted. The reason for this attitude change can be realized as the change in the banking business environment, presence and emergence of private banks and increased awareness of customers about the banking services wherein all these cases of the banking system and its management have led to main provider source of its long term benefits i.e. the customers.

Having a strategic integrated plan and compilation of the customer relationship management strategy is a basic step in order to achieve the long term goals of an organization and also to gain the satisfaction of customers. The mining and industry bank as a development (expertise) bank is one of the main tools and institutions to contribute to economic growth and development via the mining and industries development.

The developmental banks are financial and credit institutions that conduct mobilization of the long term, mid term, short term and low cost financial resources to make it via theirs, others or jointly in the line with the country's objectives of the economic development programs efficiently invest in the production activities. The duties, roles and activities of the 
developmental banks can be essentially explained in relation with the economic development process.

According to definition of the objectives and tasks of development banks it can be said that unlike the business banks customers that mainly are real individuals, ordinary citizens of the society and households, the development banks customers possess the following properties:

- Since these banks are mainly confined to developing countries, the customers of banks are also affiliated to the developing countries.

- Considering that the private sector in developing countries are poor in the beginning of economic development and even the market forces are incapable in resources allocation, the major customers of these banks are in private sector category.

- Considering that the development banks are striving to carryout development duties and strengthen entrepreneurship tasks in the private sector and thus increase the activity share of this section in the economy.

- It can be said that the vast majority of banks customers are formed by entrepreneurs and owners of small to medium sized businesses that for financial mobilization of their business (in the field of industry, mining, new technology and services) need assistance of the bank. (The explanation is that in principle in the economics it is said that the banks have an obligation to support the small businesses and the stock markets are responsible to support the big businesses.)

- In addition, customers of development banks are mainly the small and medium business owners and entrepreneurs are those people that for the evaluation of their business plans in economic, technical, administrative, financial and legal terms need the consultation of the trusted advisors of development banks.

- Even another category of the customers of development banks are the real and legal individuals that for the improvement of the industrial, mining , new technologies and services units of theirs which have already been established need the bank facilities.

- The major customers of development banks constitute the legal entities that for customer satisfaction assessment of these banks CEO and in some cases the other senior managers are considered as a representative of that legal person.

- Thus, with an aim to identify the strategic opportunities and threats faced by mining and industry bank, the internal strategic strength and weakness points of bank, determination of an appropriate strategy of the customer relationship management section, a comprehensive framework strategy based on the Fred R. David method was used.

- This framework provides the tools and methods that are appropriate for a variety of organizations in different sizes ((Aarabi, Mohammad, 2006), (Bovee, R. D. 1993)).

- In this way, after the vision and mission determination in the beginning stage, in the input stage, external factors were investigated and determined.

- Besides the internal factors of the bank were also explored and the (IFE) and (EFE) matrix were prepared.

- In the comparison and adaptation stage with the preparation of the matrix (SWOT), the customer relationship section strategies were specified that in the decision making stage with the use of the Intuitive-application strategies were prioritized as follows:

1. Conduction of effective and efficient advertisements in order to increase the public awareness of the bank activities

2. A) Development of internet and e-services

B) Reviewing the organization's bureaucratic structure in order to expand the powers, creativities and vulnerabilities

3. A) increasing the number of domestic branches and setting up the foreign branches

B) Conduction of the didactic and specialized-operating training classes for the staff

4. Planning and execution of an expertise and operational strategic plan

5. A) Increase of the banking services with resource absorption approach

B) Development of the attributive credit plans with respect to future sanctions

6. Emphasis on the reverence of the clientele in the work processes and educational programs

7. Organizing the customer oriented structure section and determining duty and powers limit

\section{Important of Strategic Planning}

With beginning of ultra-industrial period the organizational environment turned dynamic and much changed and the complexity was discussed as a dominant issue in the organizations. The changes intensified so much that validity of the 
predictive functions disappeared besides new and unexpected challenges were formed. The markets became highly competitive and the earlier and faster learning in relation to the competitors was discussed as a competitive advantage and as a result the focus of an organization was concerned towards awareness, knowledge and information ((Fred R. 2003),(Flood et al, 2002)).

Strategic management on the positioning of an organization in both the eras present and future focuses on accessing the success and implements planning, analysis, organization, execution and evaluation with one another. In this approach queries are raised about the future such as: Which are the factors affecting an organization? What are the new merits that we need to acquire them? How we should change ourselves to create the merits?

A strategic planning as the first section of strategic management assist an organization to have a cutting edge image of its industry and organization and gains an ability to realize any kind of change in its required time. This process enables managers to asses the logical results between resources allocation and selection of appropriate execution and performance indicators (Kaplan, Robert \& Norton, David, 2007). A successful strategic planning considering the planning processes and organizational learning has linked them (Vafaei, Hossein, 2004). And provides a tool in authorization of organizations so that they could compile and executive a strategy in various aspect of an organization and have a management on their strategic performance ((David et al, 2002), (Dr. Khodadad Hosseini, 2006)). In reality, the strategy direction and scope of an organization in long term, through resources arrangement during environmental changes to meet market needs and customers' expectations provides an organization an access to advantage. The most important feature of strategic planning lies in its teamwork nature. Because in the framework of such process and it is the teamwork where the belief in teamwork forms (Amir Kabir, Alireza, 1998). This process take place when the planning team members' focus on creation of a balance between available resources besides emerged and expanded opportunities (Pahlavanian, Hossein, 2006) and program content explains the goals and the means to achieve it (Vafaei, Hossein, 2004).

\section{Methodology}

For the compilation of mining and industry bank strategy a comprehensive framework of strategy compilation based on the strategic planning method of Fred R. David was used. This model assists the strategists to identify, evaluate and select the strategies. This framework possesses four main stages viz.

1- Beginning stage: In this stage the vision and mission of an organization is prepared.

2- Input stage: In this stage the main factors and information required from inside and outside of an organization to codify a strategy are identified and characterized. This stage includes the external factors evaluation matrix, internal factors evaluation matrix and competition assessment matrix.

3- Comparison and adaptation stage: At this stage the main external factors (opportunities and threats) and main internal factors (strengths and weaknesses), with the use of a tool such as SWOT matrix and internal and external matrix (IE) and SPACE matrix were compared in order to identify the strategies that were in line with mission of an organization.

4- Decision making stage: In this stage with the use of the quantitative strategic planning matrix (QSPM) different options of strategies were identified and in the comparison stage, were evaluated and judged and their relative attractiveness was determined ((Aarabi, Mohammad, 2006), (Bovee, R. D. 1993)). Table 1 indicates a comprehensive framework of strategy compilation.

Table 1: Strategy compilation comprehensive framework chart (Pahlavanian, 2006)

\begin{tabular}{|l|}
\hline Beginning stage \\
\hline 1- Determination of an organization vision and mission \\
\hline 2- Input stage \\
\hline 3- Internal factors evaluation matrix(IFE) \\
\hline 4- External factors evaluation matrix ((EFE) Comparison or adaptation stage \\
\hline 5- SWOT matrix \\
\hline 6- Internal and external matrix (IE) 6- Internal and external matrix (IE) \\
\hline 7- The decision making stage \& QSPM matrix \\
\hline
\end{tabular}




\subsection{Determination of an organization vision and mission}

The vision besides being in line with motion also creates an aspiration for the motion (Hambrick, D \& Fredrickson J 2001) and works as a map for the future direction motion of an organization (John A.et al, 1985) whereas a mission in fact is the response to this question 'what is the desirable status and future of a company and the product line?' (Konneth R, 1971) The mission describes the reason for the existence and most general objectives of an organization.

\subsubsection{Vision and mission of the mining and industry bank customers' relationship section}

"This section with acquisition of the highly motivated and skilled staff, provides financial and monetary activities related to actives of mining and industry section with respect preservation, fulfilment of customer satisfaction and considering developmental and economical objectives of a bank all around the world and with modern tools".

\subsection{Input stage}

\subsubsection{External factors evaluation matrix}

This matrix is a tool that permits the strategists to assess the environmental, economical, social, cultural, legal, technological, market condition factors in the desired time period and has a usage for the public and private organizations ((Aarabi, Mohammad, 2006), (Bovee, R. D. 1993)). This matrix is used for the information collection of public and industry environment (David, Fred R. 2003). In the following matrix, the affecting external environment factors on customers' relationship mining and industry bank section were identified and later evaluated and assessed in the opportunities and threats block due to importance.

Table 2: External factors evaluation matrix (EFE) of the mining and industry bank customers' relationship section

\begin{tabular}{|c|c|c|c|c|}
\hline Row & External factors & $\begin{array}{c}\text { Ratio } \\
(0-100)\end{array}$ & $\begin{array}{l}\text { Rating } \\
(1-4)\end{array}$ & Score \\
\hline \multicolumn{5}{|c|}{ Opportunities } \\
\hline 1 & The expansion of capital oriented approach in the industrial workshop with technology growth & 6 & 4 & 24 \\
\hline 2 & Increase in the university level education and the students' number in the university in society & 6 & 3 & 18 \\
\hline 3 & Lack of effectiveness of international sanctions & 7 & 4 & 28 \\
\hline 4 & Increase in the number of industrial workshops and production index increase in the provinces & 7 & 2 & 14 \\
\hline 5 & Increase in the number of exploitation mines in the provinces & 6 & 2 & 12 \\
\hline 6 & Increase in the industrial goods exports & 6 & 3 & 18 \\
\hline 7 & Increase in the net facilities granted by the state banks to the private sector & 4 & 3 & 12 \\
\hline 8 & Increase of internet users and new methods & 7 & 3 & 21 \\
\hline \multicolumn{5}{|c|}{ Threats } \\
\hline 1 & The lack of country's economic and political stability & 8 & 2 & 16 \\
\hline 2 & The lack of internet infrastructure and deficiency of network security & 4 & 1 & 4 \\
\hline 3 & $\begin{array}{l}\text { The strong presence of government in the banking system collection and lack of an efficient private } \\
\text { bank in the capital market }\end{array}$ & 6 & 2 & 12 \\
\hline 4 & $\begin{array}{l}\text { Lack of presence and or completion of the complementary institutions such as insurance investment } \\
\text { and rating companies }\end{array}$ & 5 & 1 & 5 \\
\hline 5 & Lack of financial resources besides enormous financial needs in a not very far future & 4 & 1 & 4 \\
\hline 6 & Existence of economical monopolies and variants & 6 & 1 & 6 \\
\hline 7 & Lack of inconsistency of the political sphere and country's economic sphere & 7 & 2 & 14 \\
\hline 8 & $\begin{array}{l}\text { Lack of transparency required for the rules and regulations and as a result existence of an inefficient } \\
\text { bureaucracy }\end{array}$ & 5 & 1 & 5 \\
\hline 9 & $\begin{array}{l}\text { Reduced importance subjection to the positions of the development institutions such as the mining and } \\
\text { industry bank and not having a suitable role in the absorption of the scarce resources and leading them } \\
\text { towards productive-industrial activities }\end{array}$ & 6 & 1 & 6 \\
\hline Total & & 100 & & 219 \\
\hline
\end{tabular}




\subsection{Internal factors evaluation matrix (IFE):}

This matrix is a tool to check the internal factors of an organization. In fact, it identifies the strength and weakness point of the organizational units. For preparation of this matrix mainly the comments and views of the managers and employees are used ((Aarabi, Mohammad, 2006), (Bovee, R. D. 1993)). And it has an application in the collection of organizational internal information in the process of strategic planning. In the below matrix the abilities of the mining and industry bank customers' relationship section are evaluated:

Table 3: Internal factors evaluation matrix (IFE) mining and industry bank customers' relationship section

\begin{tabular}{|c|c|c|c|c|}
\hline Row & Internal factors & $\begin{array}{c}\text { Ratio (0- } \\
100)\end{array}$ & $\begin{array}{c}\text { Rating } \\
(1-4)\end{array}$ & Score \\
\hline \multicolumn{5}{|c|}{ Strengths } \\
\hline 1 & Highlighting the Islamic banking approach in the production cycle & 2 & 4 & 8 \\
\hline 2 & The existence of a strong database base for processing customers information & 2 & 3 & 6 \\
\hline 3 & Observing respect and courtesy in dealing with the customers & 4 & 4 & 16 \\
\hline 4 & The diversity and development in availing banking services & 3 & 4 & 12 \\
\hline 5 & Lower loan interest in relation to the commercial bank loans & 2 & 2 & 4 \\
\hline 6 & Identifying continuous issues of the process related to the customers & 3 & 3 & 9 \\
\hline 7 & $\begin{array}{l}\text { The payment system and an appropriate compensation and diverse benefits package for } \\
\text { the employees }\end{array}$ & 3 & 3 & 9 \\
\hline 8 & $\begin{array}{l}\text { The existence and development of the human resources from skills and education } \\
\text { dimension }\end{array}$ & 3 & 4 & 12 \\
\hline 9 & $\begin{array}{l}\text { The employee participation in the decision making affair in the customer oriented } \\
\text { department }\end{array}$ & 2 & 3 & 6 \\
\hline 10 & Recognition among the international banks & 2 & 4 & 8 \\
\hline 11 & Presence of expert employees in the mine and industry field & 4 & 2 & 8 \\
\hline 12 & The existence of a transparent process in the facilities payment & 3 & 2 & 6 \\
\hline 13 & The existence of suitable educations in the specialized topics & 2 & 4 & 8 \\
\hline 14 & Support of the management from the changes in the customer oriented section & 2 & 3 & 6 \\
\hline 15 & The privilege of about 50 years of industrial development banking in the country & 2 & 4 & 8 \\
\hline 16 & Increase in the mine and industry bank facilities payment & 2 & 4 & 8 \\
\hline \multicolumn{5}{|c|}{ Weaknesses } \\
\hline 1 & $\begin{array}{l}\text { The weakness of communicational processes between the organizational sections and } \\
\text { employees of an organization }\end{array}$ & 3 & 1 & 3 \\
\hline 2 & The shortage of the number of branches throughout the country & 2 & 2 & 4 \\
\hline 3 & $\begin{array}{l}\text { The lack of employees vulnerability and flexibility of the processes based on the customers } \\
\text { demand }\end{array}$ & 3 & 2 & 6 \\
\hline 4 & $\begin{array}{l}\text { The shortage of the transformative managers having strategic thinking and reactive to the } \\
\text { environmental changes at the level of the entire organization }\end{array}$ & 4 & 2 & 8 \\
\hline 5 & Lack of the career path planner for the management positions & 4 & 2 & 8 \\
\hline 6 & $\begin{array}{l}\text { The increase in female employees and failing to comply with the industrial-mineral bank } \\
\text { environment }\end{array}$ & 2 & 2 & 4 \\
\hline 7 & Inexistence of proper education in the case of customer orientation in the branch level & 4 & 2 & 8 \\
\hline 8 & The lack of consistency in the previous and next managers policies & 4 & 2 & 8 \\
\hline 9 & The poor relationship of bank with industry and academic centres & 2 & 4 & 8 \\
\hline 10 & The intense bureaucracy & 2 & 1 & 2 \\
\hline 11 & The lack of high expertise among the personnel & 3 & 2 & 6 \\
\hline 12 & The lack of awareness and information in the absorption of customers and people & 4 & 2 & 8 \\
\hline 13 & The existence of the relationship outside the banking rules in giving credits and loan & 2 & 1 & 2 \\
\hline 14 & Defect in the organizational structure of customer oriented section & 3 & 1 & 3 \\
\hline 15 & The existence of parallel working in the customer oriented section & 4 & 2 & 8 \\
\hline 16 & Limitations in the contracts & 2 & 1 & 2 \\
\hline 17 & The lack of customer oriented thinking in the organizational culture & 4 & 2 & 8 \\
\hline 18 & $\begin{array}{l}\text { The lack of the organizational innovation, creativity and necessary organizational stimulus } \\
\text { due to the organizational structure and uncompetitive activities of the bank }\end{array}$ & 2 & 2 & 4 \\
\hline 19 & Low speed in offering services & 3 & 1 & 3 \\
\hline 20 & Weakness in the implementation of the process changes & 2 & 1 & 2 \\
\hline Total & & 100 & & 239 \\
\hline
\end{tabular}




\subsection{SWOT matrix}

the SWOT matrix is one of the important tools that the managers via this tool compare the information related to the internal and external factors and can with use of it present a variety of possible strategies $[7,8]$. The SWOT matrix consists of a two dimensional coordinates table that each of its four areas indicates a strategy category ((Bovee, R. D. 1993), (David, Fred R. 2003)).

1- Strengths opportunities (SO): the strategies for maximum use of the opportunities with utilization of the strength points

2- Weaknesses opportunities (WO): the strategies to use the potential benefits of the lying opportunities to compensate the existing weakness points

3- Strengths threats (ST): the strategies to use the strength points of an organization to avoid facing the threats

4- Weaknesses strategies (WT): the strategies to minimize the losses caused by the threats and weak points

Considering the aforesaid cases and the views of the individuals of the statistical society, the selective strategies of each section is as follows:

Table 4: SWOT matrix of the mine and industry bank customer relationship section

\begin{tabular}{|c|c|}
\hline $\begin{array}{l}\text { WT strategies } \\
\text { 1- selection of the senior executives according to the } \\
\text { organization needs and environmental changes } \\
\text { 2- overview of the bureaucracy structure of an } \\
\text { organization to expand the authorities, creativities and } \\
\text { vulnerabilities } \\
\text { 3- overview in the systems of forces absorption with } \\
\text { regards to the working environment and technological } \\
\text { changes }\end{array}$ & $\begin{array}{l}\text { WO strategies } \\
\text { 1-increasing the number of domestic branches and setting up the foreign branches } \\
\text { 2-an emphasis on the tactic knowledge transfer and proper use of the organizational amnesia } \\
\text { 3- supplying strategic human resources management plan } \\
\text { 4- organizing the structure of the customer oriented section and determining the limit of duties and } \\
\text { powers } \\
\text { 5- holding conferences and continuous meetings with the presence of major and unsatisfied bank } \\
\text { customers } \\
\text { 6- reengineering the facility and credit processes related to the customers } \\
\text { 7- conduction of the training classes and specialized-operational workshops for the employees } \\
\text { 8- increasing the research budget and acquisition of scientific advisors among the academic } \\
\text { professionals } \\
\text { 9- the establishment of team oriented culture and facilitation of the vertical and horizontal } \\
\text { communications }\end{array}$ \\
\hline $\begin{array}{l}\text { ST strategies } \\
\text { 1- Preparation and implementation of the specialized } \\
\text { and operational strategic plan } \\
\text { 2- Expanding the two-way communications with the } \\
\text { government in the line with definition of the common } \\
\text { goals } \\
\text { 3- Increasing bank services with resources absorption } \\
\text { approach } \\
\text { 4- Increasing information security networks associated } \\
\text { with the customers and bank processes }\end{array}$ & $\begin{array}{l}\text { SO strategies } \\
\text { 1- concentrating on the scientific and professional merit holders } \\
\text { 2- conduction of effective and efficient advertisements in order to increase the community public } \\
\text { awareness of the bank activities } \\
\text { 3- development of credit document plan with regard to the upcoming sanctions } \\
\text { 4- development of internet and e-services } \\
\text { 5- an emphasis on the reverence of the clientele in the work processes and educational programs } \\
\text { 6- expansion of the software and hardware substructures of an organization for the information } \\
\text { transmission ease } \\
\text { 7- creation of the banking-monetary services companies in order to perform free consulting } \\
\text { services for the applicants and mining-industrial, business and tourism investments }\end{array}$ \\
\hline
\end{tabular}

\subsection{Internal and external matrix (IE):}

considering the four determined strategic categories in the SWOT matrix and considering the region of the positioning of a company in the internal and external matrix, the offensive area strategies and suitable strategies of the competitive region are selected for the evaluation in the acceptability mean matrix, feasibility in coordination with the objectives for the selection of the strategies with the higher priorities ((Aarabi, Mohammad, 2006), (David, Fred R. 2003)).

\subsection{Decision making stage \& QSPM matrix}

Acceptability average matrix, feasibility, in coordination with the objectives: is one of the very common techniques and tools that are used in the evaluation of the strategic options and determination of the relative attractiveness of the strategies in the decision making stage. This method is intuitive and functional and with the view of the advisors of this affair is used for the more realistic determination and more operation of the strategies. This matrix identifies that which of the strategic options selected are more suitable and in fact it prioritize these strategies. In the following for the selection of the strategies with higher prioritization for the communication section with the mine and industry bank customers instead of using the quantitative QSPM - an intuitive-applied admissibility, feasibility in coordination with the said objectives that 
in which the seven selected strategies are assessed.

Table 5: Acceptability average matrix, feasibility, in coordination with the objectives for the section of mine and industry bank customer's relationship

\begin{tabular}{|c|c|c|c|c|c|}
\hline Strategy & $\begin{array}{c}\text { Acceptability average } \\
\text { Score }\end{array}$ & $\begin{array}{c}\text { Feasibility average } \\
\text { score }\end{array}$ & $\begin{array}{c}\text { In coordination with objective average } \\
\text { Score }\end{array}$ & $\begin{array}{c}\text { Total average } \\
\text { scores }\end{array}$ & Priority \\
\hline Sg1 & 2.2 & 2.5 & 1.5 & 6.2 & \\
\hline Sg2 & 3 & 3.1 & 3.5 & 9.6 & \\
\hline Sg3 & 2.25 & 3 & 1.2 & 6.45 & \\
\hline Sg4 & 4.1 & 4.25 & 4.25 & 12.6 & 4 \\
\hline Sg5 & 2.8 & 1.2 & 2.4 & 6.4 & \\
\hline Sg6 & 3.8 & 3.9 & 4.8 & 12.5 & 5 \\
\hline Sg7 & 2.3 & 3.7 & 1.1 & 7.1 & \\
\hline Sg8 & 3.9 & 4 & 4.8 & 12.7 & 3 \\
\hline Sg9 & 3.1 & 3.1 & 2.8 & 9 & \\
\hline Sg10 & 3.3 & 3 & 2.7 & 9 & \\
\hline Sg11 & 3.3 & 4.9 & 3.7 & 11.9 & 7 \\
\hline Sg12 & 3.1 & 4.8 & 4.9 & 12.8 & 2 \\
\hline Sg13 & 2.4 & 2.7 & 4 & 9.1 & \\
\hline Sg14 & 4.1 & 4.2 & 4.4 & 12.7 & 3 \\
\hline Sg15 & 3.1 & 3.3 & 2.2 & 8.6 & \\
\hline Sg16 & 3.3 & 3.6 & 2.4 & 9.3 & \\
\hline Sg17 & 2.8 & 3.9 & 2.1 & 8.8 & \\
\hline Sg18 & 4.7 & 4.8 & 4.9 & 14.4 & 1 \\
\hline Sg19 & 4.3 & 4.4 & 3.8 & 12.5 & 5 \\
\hline Sg20 & 4.1 & 3.9 & 4.8 & 12.8 & 2 \\
\hline Sg21 & 3.8 & 4.2 & 4 & 12 & 6 \\
\hline Sg22 & 3 & 3.1 & 4.5 & 10.6 & \\
\hline Sg23 & 3.2 & 2.1 & 2.4 & 7.7 & \\
\hline
\end{tabular}

Considering the SWOT matrix and acceptability average matrix, feasibility, in coordination with the objectives, the following strategies are selected for the mining and industry bank customers' relationship:

1. Conduction of effective and efficient advertisements inline with the public awareness of the bank activities

2. A) Development of the internet and e-services

B) Overview of the organization's bureaucracy structure in order to expand the powers, creativities and vulnerability

3. A) Increase in the number of domestic branches and setting up of the foreign branches

B) Conduction of the training classes and specialized-operational workshops for the employees

4. Planning and execution of the specialized and operational strategic plan

5. A) Increase in the banking services with resources absorption approach

B) The development of documented credit programs considering the future threats

6. An emphasis on the reverence of the clientele in the work processes and educational programs

7. Organization of the customer oriented section structure and determination of the duties and credit limits

\section{Conclusion and Operational Suggestions}

What is certain that this bank should in the first priority conduct in relation with the effective and efficient advertisements for the increase of the community public awareness and also carries out the redefinition and classification of its customers and also coordinates the position and the number of its branches in relation to the existing demand of the customers so that the customer satisfaction level of customers in relation to the process index of access to the services is improved.

It is necessary to mention that the customers in the survey by the mining and industry bank in relation to the position and the number of bank branches have exhibited a lower level of satisfaction. As well it seems necessary that the senior managers of the bank conduct the thinking revision in relation to their customers and bring about the culture of 
the reverence of the clientele in a characteristic form in the organizational culture.

In addition it is recommended that with consideration of the newly established sector of mining and industry bank customers relationship section in the distinct unit completely separate, in the deign of the structure of this sector with view of the tem oriented changes takes place.

And even it appears that the managers and those involved in the customer oriented section and do not remain unaware of the learning section with bilateral cooperation and interactive of the strategic human resources strategy inline with the better accountability to the customers and reengineer this educational package.

If the ratio percentage of the bank's participation in the financing of the projects is relatively appropriate; but the ration of the customers satisfaction in the survey that is carried out via the mining and industry bank is not high; therefore bank should carry out the relative to the modification of this ratio and or at least the customers realizations of this ratio and strives in the development of the banking services with higher resources absorption approach.

What is certain is that the managers and especially the managers of the customer relationship section with consideration of the country's political situation and the higher possibility of the future sanctions, should strive in the development of the documented credit programs and take a step forward in the review and execution of the program and urge a more careful strategic plan.

\section{References}

Internal statistics and information of the company

Aarabi, Seyed Mohammad, 2003, Strategic planning of the Tehran customs, Tehran, the cultural research bureau

Aarabi, Mohammad, 2006, Handwritten strategic planning, Tehran, the cultural research bureau

Ali Ahmadi, Alireza, Fathallah, Mahdi, Tajoldin, Iraj, 2003, a comprehensive vision on the strategic management: approaches, paradigm, schools, processes, models, techniques and tools, Tehran, Knowledge production.

Amir Kabir, Alireza, 1998 Strategic management, Tehran, Properties publication

Bovee, R. D. 1993, Organization and management, $5^{\text {th }}$, Reprint, New Delhi, McGraw Hill

Chandler, Alfred 1992, Strategy and structure: chapters in the American enterprise, Cambridge, MA, MIT press

Church, Kim; Smith, Road (Fall 2008), REA ontology - Based simulation models for enterprise strategic planning, Journal of information systems, Vol. 22, Issue 2.

David, Fred R. 2003 Strategic management (translation of Ali Parseian and Seyed Mohammad Aarabi) Tehran, The cultural research bureau

David, Hangar, Jay, Violon, Thomas, L 2002 the basics of strategic management (translation of Seyed Mohammad Aarabi and Davood Izadi) Tehran. The Cultural Researches Bureau

Faizi, Tahere, 2006 Principles of the organization and management, Publications of Payame Noor University

Flood, Patrick C, Dromegol, Tony, Carroll, Stephen, G. Gorman, Lim, 2002, Application management strategy (translation of Fakhruddin famous Neghdehi) Sanandaj, Kurdistan University.

Gorchels, Linda 2003, the product manager's field guide, copyright @ 2003 by Linda Gorchels, United States copyright

Hambrick D \& Fredrickson J 2001 Are you sure you have a strategy? Academy of Management Executive.

John A. Pearcell \& Richard B. Robinson (1985) in strategic management - strategy formulation and implementation

Kaplan, Robert, Norton, David, 2007, strategy map: converting the intangible assets to the tangible consequences (translation of Hossein Akbari, Masood Soltain and Amir Maleki), Tehran, Ariana Industrial research group.

Konneth R Andrews 1971 the concept of corporate strategy, Dor Jones Irwin Inc. Homewood, Illinois.

Pahlavanian, Hossein, 2006 A successful experience of the strategic management application, Nikoo method publication

Strategies of Dr. Khodadad Hosseini/ strategy compilation of post pension fund of IRIB, 2006-2007 - the Iranian strategic and productivity center, Hossein Fard Khodad, Danaeefard,. Amin Bharifar/ strategy compilation of the trade bank, the Iranian strategic and productivity center.

Vafaei, Hossein, 2004, the Iranian center of information and scientific documents. 